Chronic Obstructive Pulmonary Diseases: Journal of the COPD Foundation

\title{
Abdominal Visceral Adipose Tissue is Associated with Myocardial Infarction in Patients with COPD
}

Alejandro A. Diaz, MD, MPH ${ }^{1}$ Tom P. Young, BS ${ }^{1}$ Sila Kurugol, $\mathrm{PhD}^{2}$ Erick Eckbo, BS ${ }^{1}$ Nina Muralidhar, BS ${ }^{1}$ Joshua K. Chapman, BS ${ }^{1}$ Gregory L. Kinney, $\mathrm{PhD}^{3}$ James C. Ross, $\mathrm{PhD}^{2}$ Raul San Jose Estepar, $\mathrm{PhD}^{2}$ Rola Harmouche, $\mathrm{PhD}^{2}$ Jennifer L. Black-Shinn, $\mathrm{PhD}^{3}$ Matthew Budoff, $\mathrm{MD}^{4}$ Russell P. Bowler, MD, $\mathrm{PhD}^{5}$ John Hokanson, $\mathrm{PhD}^{3}$ and George R. Washko, $\mathrm{MD}, \mathrm{MSc}^{1}$ for the COPDGene investigators.

\section{Abstract}

Background: Cardiovascular diseases are frequent and a major cause of death in patients with chronic obstructive pulmonary disease (COPD). In the general population, various fat depots including abdominal visceral adipose tissue (VAT), subcutaneous adipose tissue (SAT), and liver fat have been linked to increased risk of cardiovascular diseases. We hypothesize that these adipose tissue compartments are associated with myocardial infarction (MI) in patients with COPD.

Methods: We collected measures of VAT and SAT areas and liver attenuation on the computed tomography scan of the chest from 1267 patients with COPD. MI was a self-reported physician-diagnosed outcome. The association between fat depots and self-reported history of MI was assessed by logistic regression analysis in which the patients within the 2 lowest tertiles of VAT and SAT areas were the reference group.

Results: Eighty three patients (6.6\%) reported a history of MI at the time of enrollment. Compared to patients who did not have an MI episode, those who had a prior MI had a higher VAT area (mean \pm SD, 303.4 \pm 208.5 vs. 226.8 $\pm 172.6 \mathrm{~cm}^{2}$; $\mathrm{P}=0.002$ ) with no differences in SAT area and liver fat. After adjustment for age, gender, obesity, pack years of smoking, hypertension, high cholesterol, and diabetes, patients within the upper tertile (vs. those in the lower tertiles) of VAT area had increased odds of MI (odds ratio [OR] 1.86, 95\% confidence interval [CI] 1.02 3.41).

Conclusion: Increased abdominal visceral fat is independently associated with a history of MI in individuals with COPD.

\footnotetext{
Abbreviations: visceral adipose tissue, VAT; subcutaneous andipose tissue, SAT; myocardial infarction, MI; computed tomography, CT; Global initiative for chronic Obstructive Lung Disease, GOLD; forced expiratory volume in 1 second, FEV $_{\mathbf{1}}$; forced vital capacity, FVC; General Electric, GE; first lumbar vertebrae, L1; liver to spleen attenuation, LSA; low attenuation areas, LAA; percent of low attenuation areas, \%LAA; standard deviation, SD; intraclass correlation coefficient, ICC; body mass index, BMI; interleukin-6, IL-6

Funding Support: This work was supported by National Institutes of Health Grants: COPDGene, R01HL089897, R01HL089856; Dr. San José Estépar, 1K25HL104085 and R01 HL116473; Dr Washko, R01 HL116473 and R01 HL107246; Dr. Diaz, K01HL118714-01 and the Brigham and Women's Hospital Minority Faculty Career Development Award.

Date of Acceptance: August 14, 2014

Citation: Diaz AA, Young TP, Kurogol S, et al. Abdominal visceral adipose tissue is associated with myocardial infarction in patients with COPD. J COPD F. 2015;2(1): 8-16. doi:http://dx.doi.org/10.15326/jcopdf.2.1.2015.0127
} 
1 Division of Pulmonary and Critical Care Medicine, Brigham and Women's Hospital, Harvard Medical School, Boston, Massachusetts

2 Surgical Planning Laboratory, Department of Radiology, Brigham and Women's Hospital, Harvard Medical School, Boston, Massachusetts

3 Department of Epidemiology, Colorado School of Public Health, University of Colorado- Denver, Aurora, Colorado

4 Los Angeles Biomedical Research Institute, Torrance, California

5 Department of Medicine, University of Colorado School of Medicine, Aurora

\section{Address correspondence to:}

Alejandro A. Diaz, MD

Division of Pulmonary and Critical Care Medicine

Department of Medicine

Brigham and Women's Hospital

75 Francis Street

Boston, MA 02115

Email: ADiaz6@Partners.org

Phone: (617) 732-5188

Fax: (617) 732-7421

\section{Keywords:}

$\mathrm{CT}$, visceral adipose tissue, COPD, myocardial infarction

\section{Introduction}

Cardiovascular diseases are frequent and linked to increased risk of hospitalization and mortality in patients with chronic obstructive pulmonary disease (COPD). ${ }^{1,2}$ Nearly $50 \%$ of the deaths in COPD are due to cardiovascular diseases. ${ }^{3}$ Although the mechanisms linking COPD and cardiovascular diseases are unclear, smoking, lung inflammation, and reduced lung function are thought to be involved. ${ }^{2}$ In the general population, increased content of adipose tissue depots including abdominal fat, ${ }^{4}$ abdominal visceral fat, ${ }^{5}$ and liver fat ${ }^{6,7}$ have also been found to be associated with coronary artery disease by potentially promoting a systemic proatherogenic and inflammatory state.

Computed tomography (CT) is a non-invasive technique which allows measurement of various fat depots. ${ }^{5-9}$ Prior investigation has shown that individuals with obstructive lung disease have an increased amount of visceral adipose tissue (VAT) measured on CT scans. ${ }^{10}$ Further high VAT content has been associated with lowgrade systemic inflammation in patients with COPD, ${ }^{11}$ which in turn may increase the risk of cardiovascular disease. The potential role of other fat compartments such as subcutaneous adipose tissue (SAT) and liver adipose tissue on the cardiovascular risk in COPD patients remain to be explored. Based on these findings, we hypothesize that body fat depots are associated with $\mathrm{MI}$ in patients with COPD. We examined CT measures of VAT, SAT, and liver adipose tissue in patients with a wide range of COPD from the COPDGene study to test this hypothesis.

\section{Methods}

We used data from the COPDGene Study, ${ }^{12}$ which was designed to assess the genetic and epidemiological associations with COPD in non-Hispanic white and African-American smokers aged 45-80 years. Individuals with active lung diseases other than COPD, emphysema, and asthma were excluded. COPDGene was approved by the internal review board at each participating center, and all patients provided written, informed consent. The current analysis was approved by the Partners HealthCare Research Committee (2007P000554).

\section{Patient Selection}

In this analysis, we selected smokers with COPD from the first 2500-data set who had Global initiative for chronic Obstructive Lung Diseases ${ }^{13}$ (GOLD) stages I-IV COPD, which is defined as a post-bronchodilator ratio of forced expiratory volume in 1 second $\left(F E V_{1}\right)$ to forced vital capacity $($ FVC) $<0.7$.

\section{Outcome and Covariates Evaluation}

We used the Medical History Questionnaire to assess the primary outcome: self-reported physician-diagnosed myocardial infarction. Patients who responded yes to the question "Have you ever been told by a physician that you have had a heart attack (MI)?" were coded as MI. High cholesterol was coded as present if the individual either self-reported high cholesterol or was on any lipid modifying drug. Diabetes was defined based on either self-reported, physician diagnosis of the condition or diabetes medication use. Hypertension was defined as follows: a) systolic blood pressure $\geq 140$ $\mathrm{mm} \mathrm{Hg}$ or diastolic blood pressure $\geq 90 \mathrm{~mm} \mathrm{Hg}$ or b) if the patient self-reported history of hypertension and was using a blood pressure modifying medication. Medications were extracted from the Medication Questionnaire. Other variables including age, gender, and smoking history were extracted from the Eligibility 
Questionnaire and Respiratory Disease Questionnaire. The questionnaires are available at www.copdgene.org.

\section{Lung Function Assessment}

Spirometric measures of lung function were performed before and after the administration of albuterol according to American Thoracic Society recommendations. ${ }^{14}$ Postbronchodilator FEV 1 and FVC were expressed as percent of predicted values. ${ }^{15}$

\section{CT Evaluation}

All participants underwent volumetric CT scanning of the chest without contrast in the supine position at coached full inspiration and relaxed exhalation. Data collected from inspiratory CT scans were used to measure adipose tissue compartments. Images were acquired with the following CT protocol: for General Electric (GE) LightSpeed-16, GE VCT-64, Siemens Sensation-16 and -64, and Philips 40- and 60-slice scanners: $120 \mathrm{kVp}, 200 \mathrm{mAs}$, and $0.5 \mathrm{~s}$ rotation time. Images were reconstructed using a standard algorithm at $0.625 \mathrm{~mm}$ slice thickness and $0.625 \mathrm{~mm}$ intervals for GE scanners; using a B31f algorithm at 0.625 (Sensation-16) or $0.75 \mathrm{~mm}$ slice thickness and $0.5 \mathrm{~mm}$ intervals for Siemens scanners; and using a B algorithm at $0.9 \mathrm{~mm}$ slice thickness and $0.45 \mathrm{~mm}$ intervals for Philips scanners. ${ }^{16}$

\section{CT Assessment of Fat Depots}

Measures of VAT area, SAT area, and liver adipose tissue were performed with in-house software by trained readers who were blinded to patients' data (Figure 1). VAT was measured on a single axial slice of the CT scan at the inferior edge of the transverse process of the first lumbar vertebrae (L1). This anatomical reference was selected because it was easy to identify and could be replicated across a large cohort of participants. The abdominal visceral fat was then identified on the selected slice and manually segmented using a predefined attenuation range of -250 and -50 Hounsfield Units. ${ }^{17}$ SAT was measured on a single slice between the pectoralis muscles and skin surface at aortic arch level. We used this site to measure SAT area because the CT field of view was smaller than the circumference of the chest. Additionally, both the aortic arch and the pectoralis muscle are easily identified in non-contrast CT scans. The reader visually identified the first axial image above the superior aspect of the aortic arch and then manually segmented the subcutaneous fat using a

\section{Figure 1. Illustration of Adipose Tissue Compartments Measured on Chest CT Scans.}

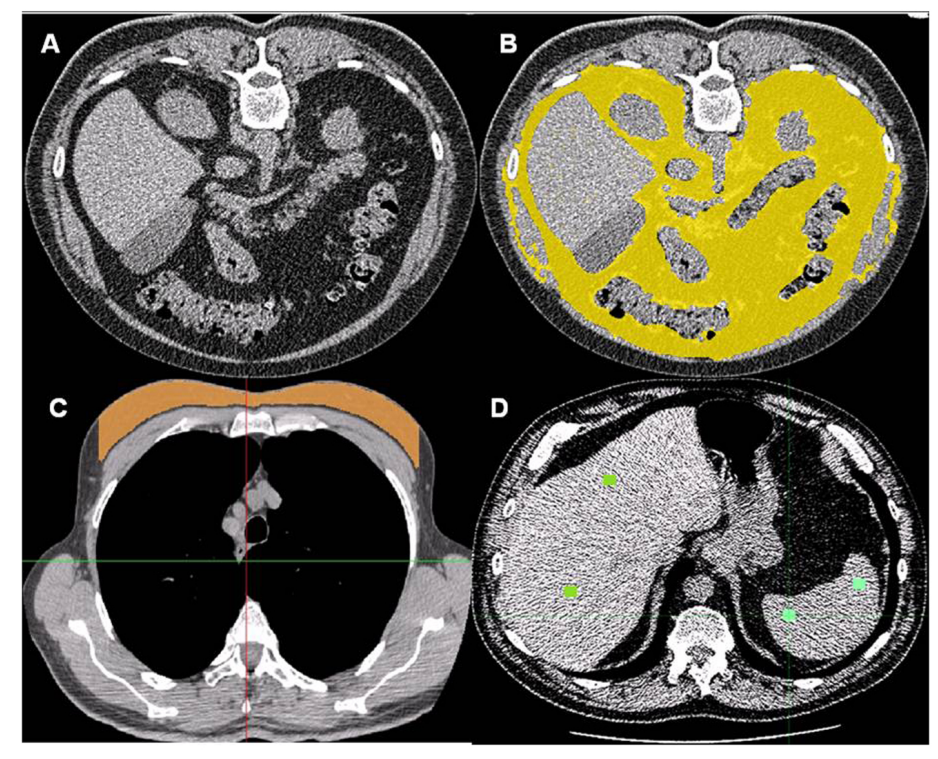

Panel $\mathbf{A}$ shows an abdominal axial slice at the first lumbar vertebrae level. The visceral adipose tissue was then segmented (B). A chest axial slice depicts the subcutaneous adipose tissue area segmented at aortic arch level (C) and the regions of interest (colored spots) on the liver and spleen in which the attenuation was measured (D).

pre-defined attenuation range of -200 and 0 Hounsfield Units. The interior of the segmented VAT and SAT were then filled automatically and the software provided the areas of these fat depots, which are reported in $\mathrm{cm}^{2}$. CT measures of VAT and SAT have been previously validated and used in clinical studies. ${ }^{8,18,19}$ Liver and spleen attenuation on CT scans were measured in 4 and 2 homogenous appearance regions of interest $(1 \mathrm{x} 1 \mathrm{~cm})$, respectively. Spleen attenuation was used as a reference. The values obtained were averaged to calculate both a patient's mean attenuation value and ratio of liver to spleen attenuation (LSA). A low ratio indicates greater fat infiltration of the liver. Fatty liver was defined as a ratio of liver to spleen attenuation equal to or less than $1.10{ }^{20}$ In random samples of 80 and 60 patients the inter-reader reproducibility of VAT and SAT was assessed, respectively.

\section{CT Quantification of Emphysema}

CT measures of low attenuation areas (LAA) were performed with open source software, Airway Inspector. Emphysema was defined as percent LAA (\%LAA) less than -950 Hounsfield Units on the CT scan. ${ }^{21}$ 


\section{Statistical Analysis}

Data is presented as mean \pm standard deviation (SD) and median interquantile range as appropriate. Inter-reader reproducibility was assessed with the intraclass correlation coefficient (ICC) test and Bland-Altman analysis. For visual purposes, regression line plots are shown. Contingency tables and Fisher exact test was performed for comparison of categorical data. Continuous variables were compared with Wilcoxon rank-sum test. The association between MI and adipose tissue depots was assessed with logistic analyses. The VAT area and SAT area distributions did not follow normality and these measures were used as binary variables, upper tertile vs. lower tertiles. We used the upper tertiles as the frequency of MI peaked in this segment of the distribution. Covariates in the model included age, gender, pack years of smoking, obesity (defined as body mass index $[\mathrm{BMI}] \geq 30$ ), high cholesterol, high blood pressure, and diabetes. A P value $<0.05$ was considered significant. Analyses were performed with SAS 9.3 (SAS Institute, Cary, NC).

\section{Results}

Out of the 2500 first COPDGene participants, 1272 had COPD. We then excluded 5 patients in whom VAT could not be measured ( 3 patients had no images available or the CT images were truncated above L1; 2 patients had a severe spinal

\section{Table 1. Characteristics of the Patients with COPD by Myocardial Infarction Status}

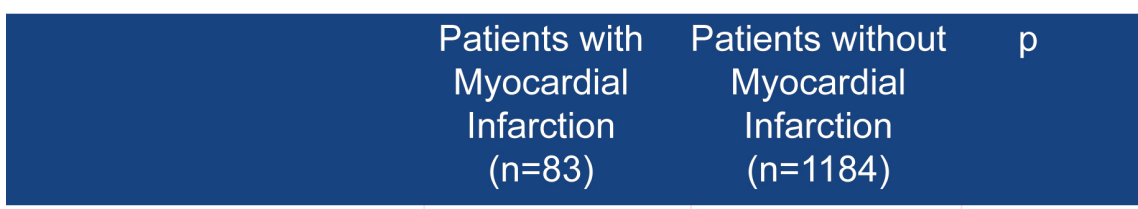

\begin{tabular}{l|c|c|c}
\hline Age, (years) & $67 \pm 8$ & $64 \pm 9$ & 0.007 \\
\hline Male Gender, (\%) & 66 & 52 & 0.02 \\
\hline BMI $\left(\mathrm{kg} / \mathrm{m}^{2}\right)$ & $29 \pm 6$ & $28 \pm 6$ & 0.19 \\
\hline Pack Years of Smoking & $63 \pm 32$ & $51 \pm 26$ & 0.0004 \\
\hline Current Smoking Status, (\%) & 33 & 36 & 0.56 \\
\hline High Cholesterol, (\%) & 83 & 43 & $<0.0001$ \\
\hline High Blood Pressure, (\%) & 63 & 52 & 0.07 \\
\hline Diabetes, (\%) & 22 & 10 & 0.003 \\
\hline Obesity, (\%) & 36 & 30 & 0.27 \\
\hline
\end{tabular}

Dyslipidemia and Cardiovascular Treatment

\begin{tabular}{|c|c|c|c|}
\hline Statins, (\%) & 62 & 28 & $<0.0001$ \\
\hline Beta Blockers, (\%) & 44 & 10 & $<0.0001$ \\
\hline ACE Inhibitors, (\%) & 30 & 12 & $<0.0001$ \\
\hline Aspirin, (\%) & 41 & 17 & $<0.0001$ \\
\hline $\mathrm{FEV}_{1}(\%$ predicted) & $56 \pm 26$ & $56 \pm 23$ & 0.82 \\
\hline FVC (\% predicted) & $81 \pm 24$ & $82 \pm 21$ & 0.35 \\
\hline $\mathrm{FEV}_{1} / \mathrm{FVC}$ Ratio & $0.51 \pm 0.14$ & $0.51 \pm 0.13$ & 0.99 \\
\hline Six-minute Walk Distance, $\mathrm{m}$ & $344 \pm 118$ & $368 \pm 137$ & 0.054 \\
\hline \%LAA, (\%) & $8.5(2.5-17.5)$ & $9.8(3.8-21.5)$ & 0.18 \\
\hline
\end{tabular}

Data are presented as mean $\pm \mathrm{SD}$, median (interquantile range), and frequency (\%). P values were estimated with Wilcoxon rank sum test and Fisher exact test as appropriate.

Missing data: Current smoking status, 6; High blood pressure, 1; Statins, 112; Beta blockers, 9; ACE inhibitors, 9; Aspirin, 112; \%LAA, 13. deformity, which led to the inclusion of lung on L1 level), leaving a final sample size of 1267 patients. Myocardial infarction was reported by 83 (6.6\%) COPD patients and their characteristics by MI status are shown in Table 1. Compared to patients with no history of MI, those with a prior MI were more likely to be older and male, and report higher frequency of cardiovascular risk factors including high cholesterol, high blood pressure, and diabetes. They also reported higher frequency of therapy for cardiovascular disease and dyslipidemia. No differences in BMI, obesity frequency, lung function, and \%LAA were found.
Reproducibility of VAT and SAT Measurements The ICC of the inter-reader reproducibility of both VAT area and SAT area was excellent: 0.99. The BlandAltman analysis did not show a systemic bias across the range of VAT area and SAT area values (Figure 2).

\section{Association Between Myocardial Infarction, Fat Depots, and Cardiovascular Risk Factors}

Compared to patients with no history of an MI, those who reported an MI had a higher VAT area (303.4 \pm 208.5 vs. $226.8 \pm 172.6 \mathrm{~cm}^{2} ; \mathrm{P}=0.002$ ). In contrast, there was no difference in the SAT area and LSA ratio between the 2 
groups (Figure 3). Patients in the upper tertile of the VAT area had a higher frequency of MI compared to those who were in the lower 2 tertiles as well as increased odds of MI (odds ratio [OR], 2.66 [95\% confidence interval (CI) 1.70 - 4.17]). No association between MI and either SAT area or fatty liver (LSA ratio $\leq 1.1$ ) was found (Table 2 ). We then used VAT as predictor along with other covariates for MI in multivariate regression.

In univariate analyses for MI, increasing age, increasing pack years of smoking, male sex, high blood pressure, high cholesterol, and diabetes increased the odds of MI by a varying degree (Table 3). After adjustment for other cardiovascular risk factors, the association between MI and VAT area was attenuated but remained significant (OR 1.86, [1.02-3.41]) (Table 4). In an additional model to account for exercise and lung function as confounding the relationship between MI and VAT area, we included age, gender, BMI, six-minute walk, and $\mathrm{FEV}_{1} \%$ predicted. In this model, the relationship between MI and VAT area was significant (OR 2.78, [1.45 - 5.30]; $\mathrm{P}=0.002)$.

\section{Discussion}

In this study we collected CT measures of abdominal visceral fat and subcutaneous fat in patients with COPD to assess the relationship between these adipose tissue depots and MI. We found that the patients who had a history of an MI had larger abdominal visceral fat content than those who did not report this event. After adjustment for relevant covariates, patients within the upper tertile of VAT had increased odds of having an MI.

Several studies have documented that an increased amount of visceral fat, fatty liver disease, and lower CT attenuation of abdominal visceral fat and subcutaneous fat are related to cardiometabolic risk and cardiovascular diseases in different populations. $5,6,19,22$ In patients with COPD, an altered body composition has been observed with a relative increase in fat mass and visceral fat. ${ }^{10}$ Also in COPD patients, an increased epicardial adipose

\section{Figure 2. Inter-reader Reproducibility of Computed Tomographic Measures of Abdominal Visceral Adipose Tissue and Subcutaneous Adipose Tissue}
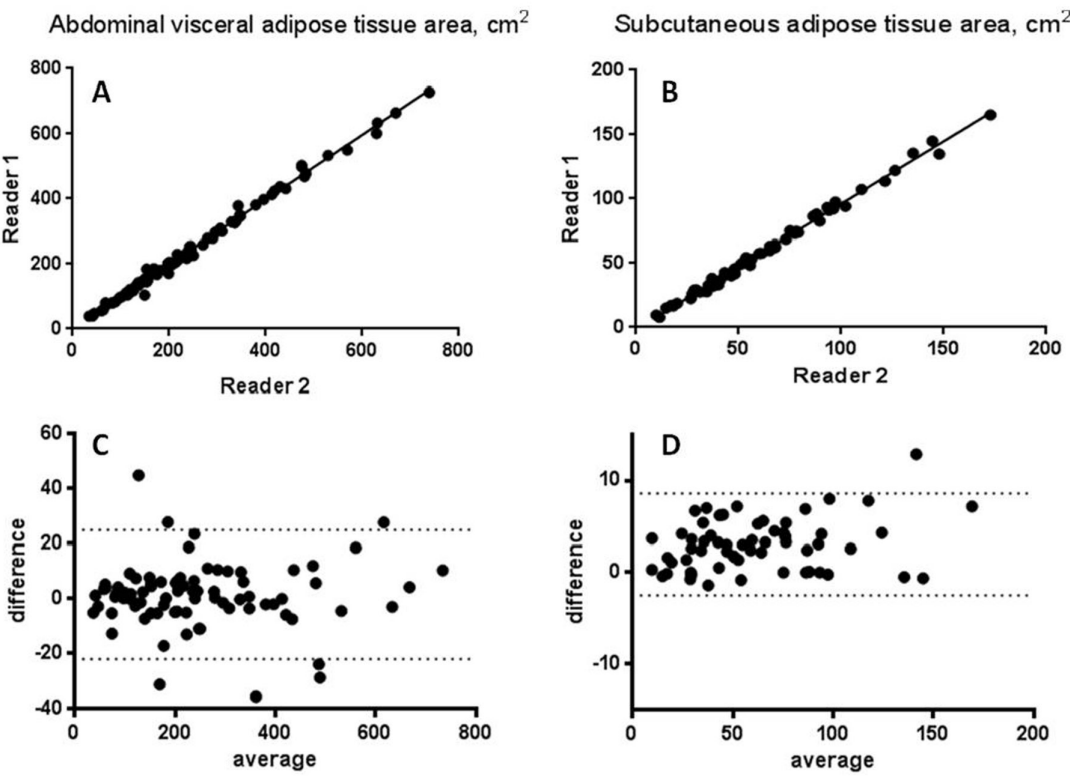

Regression line (A, B) and Bland-Altman (C, D) plots of inter-reader reproducibility of computed tomographic (CT) measures of abdominal visceral adipose tissue (VAT) area and subcutaneous adipose tissue (SAT) area between 2 readers. The inter-reader reproducibility of VAT and SAT areas was excellent (Intraclass correlation coefficient for both, 0.99).
Figure 3. Abdominal Visceral Adipose Tissue Area, Subcutaneous Adipose Tissue Area and Liver to Spleen Attenuation Ratio Data in COPD Individuals by Myocardial Infarction Status.

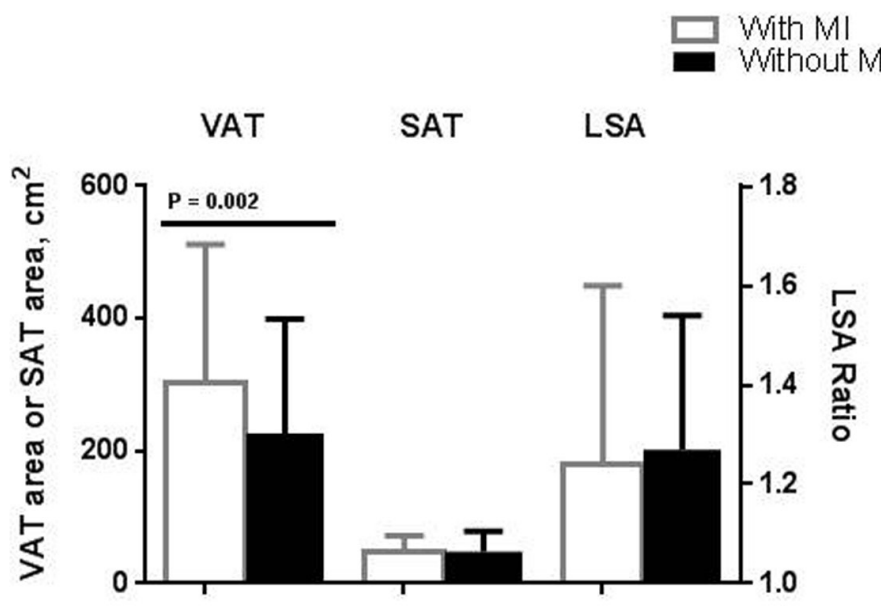

Liver to spleen attenuation ratio: right y-axis. Data are presented as mean \pm SD Abdominal visceral adipose tissue,VAT; asubcutaneous adipose tissue, SAT; liver to spleen attenuation, LSA; myocardial infarction, MI; 


\section{Table 2. Association Between Myocardial Infarction and CT Measures of Fat Depots}

\begin{tabular}{l|c|c|c|c}
\hline Fat Tissue Depot & $\begin{array}{c}\text { Patients Total / } \\
\text { No. with Ml }\end{array}$ & OR $(95 \% \mathrm{Cl})$ & $\mathrm{p}$ \\
\hline Abdominal Visceral Fat Area & & & & \\
\hline Upper Tertile & $423 / 46$ & 10.9 & $2.66(1.70-4.17)$ & $<0.0001$ \\
\hline Two Lower Tertiles & $844 / 37$ & 4.4 & Ref & \\
\hline
\end{tabular}

Subcutaneous Fat Area

\begin{tabular}{l|l|l|c|c}
\hline Upper Tertile & $417 / 27$ & 6.5 & $0.98(0.61-1.58)$ & 0.94 \\
\hline Two Lower Tertiles & $836 / 55$ & 6.6 & Ref & \\
\hline
\end{tabular}

Liver Fat

\begin{tabular}{l|c|c|c|c}
\hline Liver to Spleen Ratio $\leq 1.1$ & $239 / 17$ & 7.1 & $1.11(0.64-1.93)$ & 0.71 \\
\hline Liver to Spleen Ratio >1.1 & $1007 / 65$ & 6.5 & Ref & \\
\hline
\end{tabular}

Missing data, subcutaneous fat area, 14; liver to spleen ratio, 21.

\section{Table 3. Univariate Analyses for Self-reported Myocardial Infarction in COPD Participants}

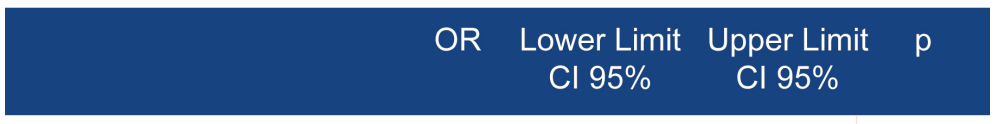

\begin{tabular}{lcccc} 
Age, years & 1.04 & 1.01 & 1.07 & 0.005 \\
\hline Male gender & 1.78 & 1.11 & 2.85 & 0.02 \\
\hline Obesity & 1.30 & 0.82 & 2.07 & 0.27 \\
\hline Pack Years of Smoking, per 10 & 1.14 & 1.06 & 1.22 & 0.0002 \\
\hline Current Smoking Status & 0.85 & 0.53 & 1.37 & 0.52 \\
\hline High Blood Pressure & 1.56 & 0.99 & 2.47 & 0.06 \\
\hline High Cholesterol & 6.45 & 3.59 & 11.58 & $<0.0001$ \\
\hline Diabetes & 2.39 & 1.37 & 4.16 & 0.002 \\
\hline \hline
\end{tabular}

\section{Table 4. Multivariate Model for Self-reported Myocardial Infarction in COPD Participants}

\begin{tabular}{|c|c|c|c|c|}
\hline Variable & OR & $\begin{array}{l}\text { Lower Limit } \\
\qquad \text { Cl } 95 \%\end{array}$ & $\begin{array}{l}\text { Upper Limit } \\
\text { CI } 95 \%\end{array}$ & $\begin{array}{c}\mathrm{p} \\
\text { Value }\end{array}$ \\
\hline $\begin{array}{l}\text { Abdominal Visceral Fat, } \\
\text { Upper tertile }\end{array}$ & 1.86 & 1.02 & 3.41 & 0.04 \\
\hline Age, years & 1.01 & 0.97 & 1.04 & 0.76 \\
\hline Male gender & 1.18 & 0.66 & 2.08 & 0.58 \\
\hline Obesity & 0.68 & 0.39 & 1.18 & 0.17 \\
\hline Pack Years of Smoking, per 10 & 1.10 & 1.01 & 1.19 & 0.02 \\
\hline High Blood Pressure & 1.16 & 0.72 & 1.89 & 0.54 \\
\hline High Cholesterol & 5.39 & 2.91 & 9.99 & $<0.0001$ \\
\hline Diabetes & 1.30 & 0.72 & 2.37 & 0.39 \\
\hline
\end{tabular}

Hosmer and Lemeshow Goodness-of-Fit Test, $\mathrm{P}=0.59$ tissue has been documented and found to be directly related to coronary artery calcification, ${ }^{23}$ which is used for cardiovascular risk assessment. We have expanded this prior knowledge by demonstrating that stable COPD patients with history of an MI had higher CT VAT content and that the highest VAT content was associated with increased odds of MI.

In our study, we found that the association between reported MI and CT measures of VAT area was independent of other known cardiovascular risk factors including age, sex, high blood pressure, high cholesterol, smoking intensity, obesity, and diabetes, and of lung function and exercise capacity. This finding is consistent with a prior study in which increased visceral fat was related to higher odds of CT-based coronary artery disease. ${ }^{5}$ However, a recent study $^{24}$ did not find such a relationship. Differences in population demographic, cardiovascular risk profile and outcome ascertainment between the latter and our study may explain this discrepancy. The question is then why abdominal visceral fat can increase the odds of MI in patients with COPD beyond the factors included in our modeling.

VAT is considered a proatherogenic fat depot and a source of mediators of inflammation. ${ }^{11}$ For example, increases in visceral fat have been associated with increased interleukin-six (IL-6) levels in patients with COPD. ${ }^{11}$ A low-grade systemic inflammation is in turn associated with cardiovascular diseases including ischemic heart disease ${ }^{25}$ and IL- 6 blood levels were found to be higher among COPD patients with heart disease. ${ }^{26}$ Additionally, visceral fat was positively related to levels of plasminogen activator inhibitor type 1 , a fibrinolytic regulation factor. ${ }^{27}$ While we do not have data on these biomarkers, we speculate that a COPD patient's VAT content might be a unique pathogenic fat depot potentially involved in those biomarker pathways.

We found no association between MI, subcutaneous fat area and fatty liver measured on CT scans. This finding might reflect differences in the biological activity related to proatherogenic or inflammatory mediators among the adipose tissue depots we assessed. Omental fat releases more IL- 6 than subcutaneous $\mathrm{fat}^{28}$ and while VAT was associated with the level of plasminogen activator inhibitor type 1 , subcutaneous fat was not. ${ }^{27}$ Our findings are in agreement with the notion that among these assessed adipose tissue compartments visceral fat seems to have a unique pathogenic role on cardiovascular diseases, but more data are needed to understand 
the complex relationship between these various adipose tissue depots and cardiovascular outcomes. Since VAT content can be modified by diet and exercise, ${ }^{29}$ our findings may have clinical implications. COPD patients with a high risk for MI can benefit from interventions aimed to reduce VAT content.

Addressing the mechanisms leading to an increased VAT content in COPD patients with a history of an MI is out of the scope of our study. Other investigators have demonstrated several potential mechanisms of fat accumulation in humans including inflammation, hypertryglyceridemia, and reduced glucose utilization. ${ }^{30}$

Several limitations should be noted. There may be a selection bias due to the inclusion of patients who survived a heart attack and thus our estimates should be interpreted with caution. The outcome of interest and cardiovascular risk factors such as high blood pressure, cholesterol level, and diabetes was a mixing of self-reported physician diagnoses and self-reported patient medication use. Additionally, the timing of these diagnoses was not recorded by the COPDGene Study. Self-reporting cardiovascular diseases has an inherent recall bias. ${ }^{31}$ However, as expected, high cholesterol and diabetes were higher among individuals with a history of an MI. We used a single cross-sectional measure of adipose tissue from existing chest CT scans. While this approach avoids additional exposure to radiation and is similar to that used in prior studies, it does not provide information about the heterogeneity of adipose tissue compartments. Despite this limitation, we observed a strong relationship between our measure of VAT and BMI $(r=0.68, P<0.0001)$, which was comparable to that from abdominal CT scans. ${ }^{9}$ Similarly, SAT was also associated with BMI $(\mathrm{r}=0.71, \mathrm{P}<0.0001)$. Finally, our study is a cross-sectional analysis of the data and determining causality of the relationship of interest is not possible. The relationship we found is the basis for more research in the emerging field of extrapulmonary manifestations of COPD.

In summary, in this study we found that COPD patients with an MI had higher abdominal visceral fat content than those with no prior history of an MI. Higher abdominal visceral fat content was independently associated with increased odds of a history of an MI. Further studies are warranted to assess the potential mechanisms linking MI and abdominal visceral fat in this population.

\section{Acknowledgements}

Author contributions: Conception and design of this study and creation, revision, and final approval of this manuscript: AAD, TPY, SK, EE, NM, JKC, GLK, JCR, RSJ, RH, JBS, MB, RPB, JH, GRW; Analysis and interpretation: AAD, JBS, RPB, GRW; Acquisition and process of the data: AAD, TPY, SK, EE, NM, JKC, JCR, $\mathrm{RH}$; Drafting the manuscript for important intellectual content: AAD, RPB, JH, GRW. Dr. Diaz takes full responsibility for the content of the manuscript, including the data and analysis. The sponsor had no role in designing, analyzing, writing, or reporting this work.

\section{Declaration of Interest}

Drs. Diaz, Kurugol, San José Estépar, Harmouche and Misters Young, Eckbo, Chapman, Ross, and Miss Muralidhar have no conflicts of interest to disclose. Dr. Washko has received consulting fees from Spiration, Inc, and his spouse is an employee of Merck \& Co, Inc. 


\section{References}

1. Sin DD, MacNee W. Chronic obstructive pulmonary disease and cardiovascular diseases: a "vulnerable" relationship. Am J Respir Crit Care Med. 2013; 187(1):2-4. doi: http://dx.doi.org/10.1164/rccm.201210-1953ED

2. Van Eeden S, Leipsic J, Paul Man SF, Sin DD. The relationship between lung inflammation and cardiovascular disease. Am J Respir Crit Care Med. 2012;186(1):11-16. doi: http://dx.doi.org/10.1164/rccm.201203-0455PP

3. Sin DD, Anthonisen NR, Soriano JB, Agusti AG. Mortality in COPD: Role of comorbidities. Eur Respir J. 2006; 28(6):12451257. doi: http://dx.doi.org/10.1183/09031936.00133805

4. Canoy D, Boekholdt SM, Wareham N, et al. Body fat distribution and risk of coronary heart disease in men and women in the European Prospective Investigation Into Cancer and Nutrition in Norfolk cohort: a population-based prospective study. Circulation. 2007;116(25):2933-2943. doi: http://dx.doi.org/10.1161/CIRCULATIONAHA.106.673756

5. Marques MD, Santos RD, Parga JR, et al. Relation between visceral fat and coronary artery disease evaluated by multidetector computed tomography. Atherosclerosis. 2010;209(2):481-486. doi: http://dx.doi.org/10.1016/j.atherosclerosis.2009.10.023

6. Kim D, Choi SY, Park EH, et al. Nonalcoholic fatty liver disease is associated with coronary artery calcification. Hepatology. 2012;56(2):605-613. doi: http://dx.doi.org/10.1002/hep.25593

7. Choi SY, Kim D, Kim HJ,et al. The relation between nonalcoholic fatty liver disease and the risk of coronary heart disease in Koreans. Am J Gastroenteral. 2009;104(8):1953-1960. doi: http://dx.doi.org/10.1038/ajg.2009.238

8. Yoshizumi T, Nakamura T, Yamane M, et al. Abdominal fat: standardized technique for measurement at CT. Radiology.1999;211(1):283-286.

doi: http://dx.doi.org/10.1148/radiology.211.1.r99ap15283

9. Snijder MB, Visser M, Dekker JM, et al. The prediction of visceral fat by dual-energy X-ray absorptiometry in the elderly: a comparison with computed tomography and anthropometry. Int J Obes Relat Metab Disord. 2002; 26(7):984-993.

10. Furutate R, Ishii T, Wakabayashi R, et al. Excessive visceral fat accumulation in advanced chronic obstructive pulmonary disease. Int J Chron Obstruct Pulmon Dis. 2011;6:423-430.

11. van den Borst B, Gosker HR, Koster A, et al. The influence of abdominal visceral fat on inflammatory pathways and mortality risk in obstructive lung disease. Am J Clin Nutr. 2012; 96(3):516526. doi: http://dx.doi.org/10.3945/ajcn.112.040774

12. Regan EA, Hokanson JE, Murphy JR, et al. Genetic Epidemiology of COPD (COPDGene) study design. COPD. 2010;7(1):32-43. doi: http://dx.doi.org/10.3109/15412550903499522

13. Rabe KF, Hurd S, Anzueto A, et al. Global strategy for the diagnosis, management, and prevention of chronic obstructive pulmonary disease: GOLD executive summary. Am J Respir Crit Care Med. 2007;176(6):532-555.

doi: http://dx.doi.org/10.1164/rccm.200703-456SO

14. American Thoracic Society. Standardization of spirometry, 1994 Update. Am J Respir Crit Care Med. 1995, 152(3):1107-1136. doi: http://dx.doi.org/10.1164/ajrccm.152.3.7663792
15. Hankinson JL, Odencrantz JR, Fedan KB. Spirometric reference values from a sample of the general U.S. population. Am J Respir Crit Care Med. 1999;159(1):179-187. doi: http://dx.doi.org/10.1164/ajrccm.159.1.9712108

16. Diaz AA, Han MK, Come CE, et al. Effect of emphysema on CT scan measures of airway dimensions in smokers. Chest. 2013;143(3):687-693.

17. Chung SJ, Kim D, Park MJ, et al. Metabolic syndrome and visceral obesity as risk factors for reflux oesophagitis: a crosssectional case-control study of 7078 Koreans undergoing health check-ups. Gut. 2008;57(10):1360-1365. doi: http://dx.doi.org/10.1136/gut.2007.147090

18. Rossner S, Bo WJ, Hiltbrandt E, et al. Adipose tissue determinations in cadavers--a comparison between crosssectional planimetry and computed tomography. Int $J$ Obes. 1990;14(10):893-902.

19. Fox CS, Massaro JM, Hoffmann U, et al. Abdominal visceral and subcutaneous adipose tissue compartments: association with metabolic risk factors in the Framingham Heart Study. Circulation. 2007;116(1):39-48. doi: http://dx.doi.org/10.1161/CIRCULATIONAHA.106.675355

20. Iwasaki M, Takada Y, Hayashi M, et al. Noninvasive evaluation of graft steatosis in living donor liver transplantation. Transplantation. 2004;78(10):1501-1505. doi: http://dx.doi.org/10.1097/01.TP.0000140499.23683.0D

21. Gevenois PA, de Maertelaer V, De Vuyst P, Zanen J, Yernault JC. Comparison of computed density and macroscopic morphometry in pulmonary emphysema. Am J Respir Crit Care Med. 1995;152(2):653-657. doi: http://dx.doi.org/10.1164/ajrccm.152.2.7633722

22. Rosenquist KJ, Pedley A, Massaro JM, et al. Visceral and subcutaneous fat quality and cardiometabolic risk. JACC Cardiovas Imaging. 2013;6(7):762-771. doi: http://dx.doi.org/10.1016/j.jcmg.2012.11.021

23. Zagaceta J, Zulueta JJ, Bastarrika G, et al. Epicardial adipose tissue in patients with chronic obstructive pulmonary disease. PloS One. 2013; 8(6):e65593. doi: http://dx.doi.org/10.1371/journal.pone.0065593

24. Shimamoto Y, Mizukoshi M, Kuroi A, et al. Is visceral fat really a coronary risk factor? A multi-detector computed tomography study. Int Heart J. 2013, 54(5):273-278. doi: http://dx.doi.org/10.1536/ihj.54.273

25. Sin DD, Man SF. Why are patients with chronic obstructive pulmonary disease at increased risk of cardiovascular diseases? The potential role of systemic inflammation in chronic obstructive pulmonary disease. Circulation. 2003; 107(11):1514-1519. doi: http://dx.doi.org/10.1161/01.CIR.0000056767.69054.B3

26. Miller J, Edwards LD, Agusti A, et al. Comorbidity, systemic inflammation and outcomes in the ECLIPSE cohort. Respir Med. 2013, 107(9):1376-1384.

doi: http://dx.doi.org/10.1016/j.rmed.2013.05.001

27. Shimomura I, Funahashi T, Takahashi M, et al. Enhanced expression of PAI-1 in visceral fat: possible contributor to vascular disease in obesity. Nat Med. 1996; 2(7):800-803. doi: http://dx.doi.org/10.1038/nm0796-800 
28. Fried SK, Bunkin DA, Greenberg AS. Omental and subcutaneous adipose tissues of obese subjects release interleukin-6: depot difference and regulation by glucocorticoid. J Clin Endocrinol Metab. 1998; 83(3):847-850.

doi: http://dx.doi.org/10.1210/jcem.83.3.4660

29. Janssen I, Fortier A, Hudson R, Ross R. Effects of an energyrestrictive diet with or without exercise on abdominal fat, intermuscular fat, and metabolic risk factors in obese women. Diabetes Care. 2002; 25(3):431-438.

doi: http://dx.doi.org/10.2337/diacare.25.3.431

30. Klimcakova E, Roussel B, Kovacova Z, et al. Macrophage gene expression is related to obesity and the metabolic syndrome in human subcutaneous fat as well as in visceral fat. Diabetologia. 2011;54(4):876-887.

doi: http://dx.doi.org/10.1007/s00125-010-2014-3

31. Barr EL, Tonkin AM, Welborn TA, Shaw JE. Validity of selfreported cardiovascular disease events in comparison to medical record adjudication and a statewide hospital morbidity database: the AusDiab study. Intern Med J. 2009; 39(1):49-53. doi: http://dx.doi.org/10.1111/j.1445-5994.2008.01864.x 